\title{
Polycomb regulation is coupled to cell cycle transition in pluripotent stem cells
}

\author{
Helena G. Asenjo ${ }^{1,2,3}$, Amador Gallardo ${ }^{1,2,3}$, Lourdes López-Onieva ${ }^{1,4}$, Irene Tejada ${ }^{1,2,3}$, \\ Jordi Martorell-Marugán ${ }^{1,5}$, Pedro Carmona-Sáez ${ }^{1}$, David Landeira ${ }^{1,2,3 *}$
}

\begin{abstract}
When self-renewing pluripotent cells receive a differentiation signal, ongoing cell duplication needs to be coordinated with entry into a differentiation program. Accordingly, transcriptional activation of lineage specifier genes and cell differentiation is confined to the $\mathrm{G}_{1}$ phase of the cell cycle by unknown mechanisms. We found that Polycomb repressive complex 2 (PRC2) subunits are differentially recruited to lineage specifier gene promoters across cell cycle in mouse embryonic stem cells ( $m E S C s$ ). Jarid2 and the catalytic subunit Ezh2 are markedly accumulated at target promoters during $S$ and $G_{2}$ phases, while the transcriptionally activating subunits EPOP and EloB are enriched during $G_{1}$ phase. Fluctuations in the recruitment of PRC2 subunits promote changes in RNA synthesis and RNA polymerase II binding that are compromised in Jarid2 -/- mESCs. Overall, we show that differential recruitment of PRC2 subunits across cell cycle enables the establishment of a chromatin state that facilitates the induction of cell differentiation in $\mathrm{G}_{1}$ phase.
\end{abstract}

\section{INTRODUCTION}

Deciphering the molecular mechanisms regulating pluripotent stem cell differentiation is of fundamental importance to understand mammalian development and for safe application of pluripotent stem cell-based therapies (1). Self-renewing mouse embryonic stem cells (mESCs) can be derived from the developing mouse blastocyst and provide a well-established system to study the molecular basis of pluripotency and early development. mESCs can differentiate into all cell types of the adult organism. However, the ability of individual mESCs within the population to respond to differentiation stimuli can be markedly different (2-4). This reveals a key aspect of the regulation of pluripotent cell differentiation and poses an important handicap for the application of stem cell-based therapies to humans. The features determining the responsiveness of individual cells to differentiation cues are mostly unknown and are currently a subject of intense debate. Accumulated evidence indicates that transcriptional activation of lineage specifier genes and cell differentiation in pluripotent cells is confined to the $\mathrm{G}_{1}$ phase of the cell cycle (5-8). This observation partly explains the observed functional heterogeneity of pluripotent cell populations and highlights a very important regulatory feature of stem cell differentiation. Despite its obvious relevance, very little is known about the molecular mechanisms underlying this type of regulation (9).

Polycomb group (PcG) proteins are a hallmark of epigenetic control in eukaryotes and key regulators of mammalian development, cancer progression, and stem cell differentiation $(10,11)$. In mESCs, PcG proteins associate to form Polycomb repressive complexes 1 and 2 (PRC1 and PRC2) that catalyze H2AK119 monoubiquitination and H3K27 methylation, respectively (11). PRCs bind and repress hundreds of developmental regulator genes that will be activated later during cell differentiation $(12,13)$. In mESCs, PRC target repressed genes display nucleosomes modified with functionally op-

\footnotetext{
${ }^{1}$ Centre for Genomics and Oncological Research (GENYO), Avenue de la llustración 114, 18016 Granada, Spain. ${ }^{2}$ Department of Biochemistry and Molecular Biology II, Faculty of Pharmacy, University of Granada, Granada, Spain. Instituto de Investigación Biosanitaria ibs.GRANADA, Hospital Virgen de las Nieves, Granada, Spain. ${ }^{4}$ Department of Biochemistry and Molecular Biology I, Faculty of Sciences, University of Granada, Granada, Spain. ${ }^{5}$ Atrys Health S.A., Barcelona, Spain.

*Corresponding author. Email: davidlandeira@ugr.es
}

posing histone modifications including $\mathrm{H} 3 \mathrm{~K} 4 \mathrm{me} 3$ and $\mathrm{H} 3 \mathrm{~K} 27 \mathrm{me} 3$ (hence, the designation of bivalent chromatin), leaky production of transcripts, and binding of poised RNAPII (RNA polymerase II) phosphorylated on $\mathrm{Ser}^{5}$ ( $\mathrm{Ser}^{5}$-RNAPII) (14-17). PRC2 is typically composed by core subunits Eed, Suz12, Rbbp4/7, and Ezh1/2 of which the last one harbors the histone methyltransferase catalytic function (11). PRC2 function is regulated by nonstoichiometric accessory subunits that are differentially expressed during development (11). mESCs express high levels of Jarid2 that recruits and enhances PRC2 activity $(11,18-22)$. In addition, mESCs express the PRC2-interacting protein EPOP, which mediates recruitment of EloB and promote low-level transcription of bivalent genes (23). It has been proposed that Jarid2 and EPOP form mutually exclusive complexes (23). In agreement, studies of $\mathrm{PcG}$ proteins interactome have shown the existence of at least two types of PRC2 subcomplexes, one containing EPOP and PCL1-3 (Polycomb-like proteins 1 to 3 ) and another one containing Jarid 2 and Aebp2 (11). They have been proposed to be termed PRC2.1 and PRC2.2, respectively (24). The functional relevance of PRC2 subcomplexes specialization remains unknown.

In this study, we asked whether chromatin regulation by PRC2 was linked to the preference of pluripotent cells to enter differentiation in $G_{1}$ phase. We found that recruitment of PRC2.1 complex to target promoters is favored in $\mathrm{G}_{1}$ phase, while binding of PRC2.2 complex increases during $\mathrm{S}$ and $\mathrm{G}_{2}-\mathrm{M}$ phases, leading to gradual accumulation of the catalytic subunit Ezh2 at bivalent promoters. This is accompanied by enhanced gene repression and accumulation of paused Ser ${ }^{5}$-RNAPII at bivalent promoters during $S$ and $\mathrm{G}_{2}-\mathrm{M}$ phases. This cell cycle-dependent regulation is particularly evident at pioneering lineage specifiers, whose tight regulation is hindered in Jarid2 _/- mESCs. Together, our results strongly suggest that differential recruitment of PRC2 complexes across cell cycle is key to establish a chromatin state that facilitates the induction of cell differentiation in $G_{1}$ phase.

\section{RESULTS \\ Recruitment of Ezh2 to bivalent promoters increases during $S$ and $G_{2}-M$ phases}

We established wild-type mESCs that stably express the fluorescent ubiquitination-based cell cycle indicator (FUCCI) reporter system 
(FUCCI-mESCs) (fig. S1A) (25)and used flow cytometry to isolate highly enriched populations of cells in $\mathrm{G}_{1}(83 \pm 2 \%)$, $\mathrm{S}(55 \pm 1 \%)$, and $G_{2}-M$ phases $(81 \pm 1 \%)$ (see Methods and table S1) (Fig. 1A). Genome-wide analysis of Ezh2 binding by chromatin immuno- precipitation followed by sequencing (ChIP-seq) readily revealed the prevalence of recruitment of Ezh2 to chromatin in $S$ and $\mathrm{G}_{2}-\mathrm{M}$ phases compared to $G_{1}$ phase (Ezh2 binding peaks: 6316 in $\mathrm{G}_{1} ; 9630$ in $\mathrm{S}$; and 15,967 in $\mathrm{G}_{2}-\mathrm{M}$ ) (table S2). Using published data, we established

A

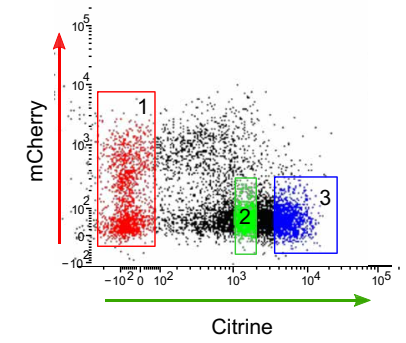

B

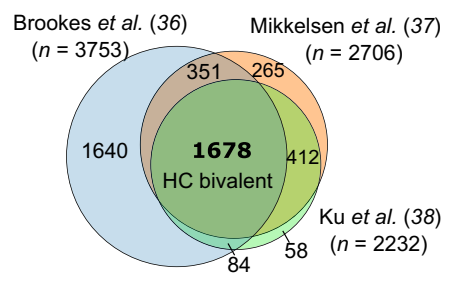

$\mathbf{F}$

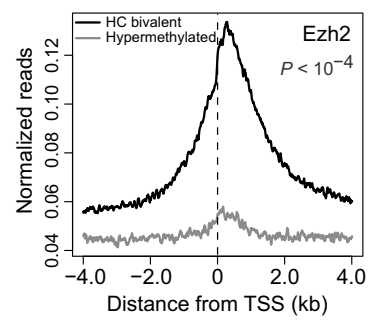

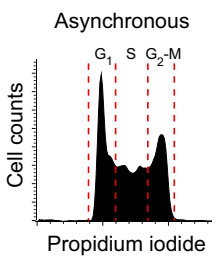

C

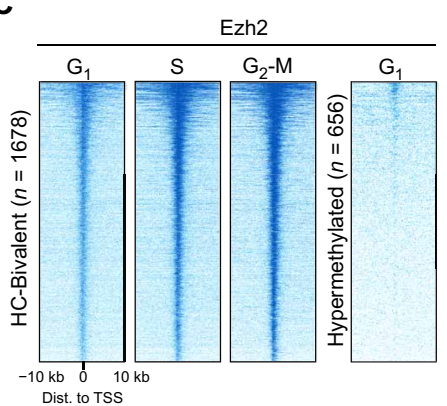

G

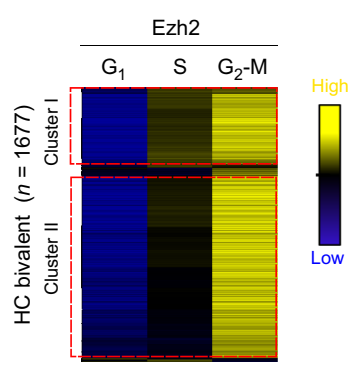

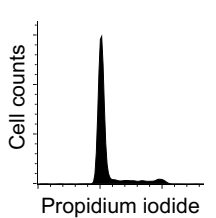

D

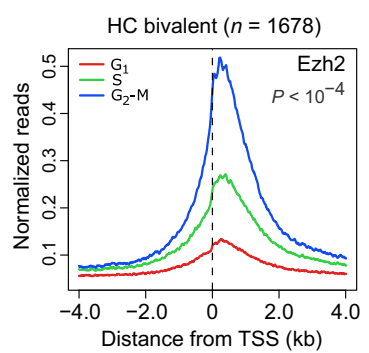

Gate 2

Gate 3
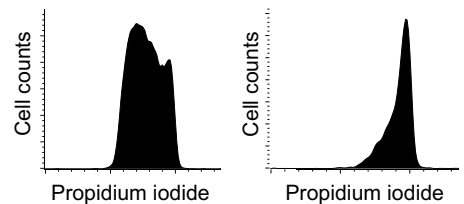

E

H
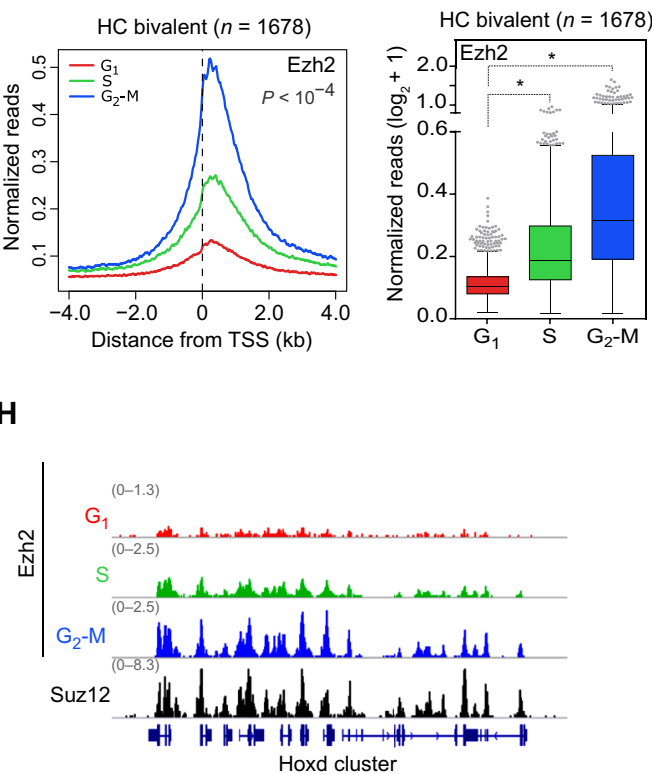

$J$

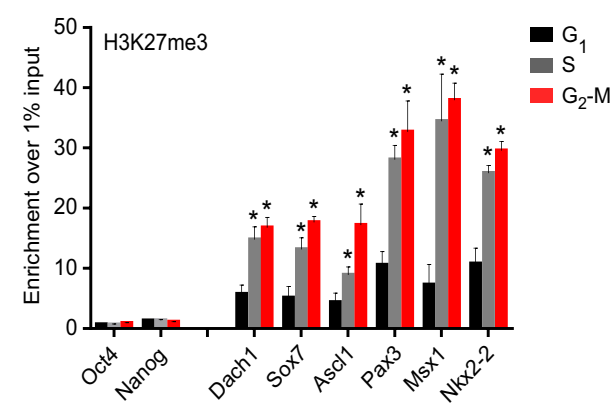

Fig. 1. Recruitment of the PRC2 core subunit Ezh2 to bivalent genes increases during $\mathbf{S}$ and $\mathbf{G}_{2}-\mathbf{M}$ phases of the cell cycle. (A) Flow cytometry dot plot analysis of FUCCI-mESCs indicating sorting gates used to obtain cell populations enriched in $\mathrm{G}_{1}$ (Gate 1), $\mathrm{S}$ (Gate 2), and $\mathrm{G}_{2}-\mathrm{M}$ (Gate 3) cell cycle phases (left). Sorted cells were stained with propidium iodide and analyzed by flow cytometry (right). (B) Venn diagrams of bivalent genes previously published in (36-38). (C) Heatmaps of normalized Ezh2 ChIP-seq reads around the TSS of HC bivalent promoters at different cell cycle phases. Heatmap of hypermethylated promoters is shown as a negative control. (D) Average

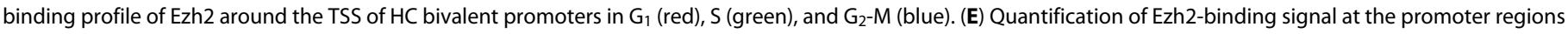
$(-0.5$ to $+1.5 \mathrm{~kb}$ relative to TSS) of HC bivalent genes in indicated cell cycle phases. (F) Average binding profile of Ezh2 around the TSS of HC bivalent (black) and hypermethylated (gray) promoters in $\mathrm{G}_{1}$ phase. (G) Hierarchical clustering analysis of binding of Ezh2 to the promoter region ( -0.5 to $+1.5 \mathrm{~kb}$ relative to TSS) of $\mathrm{HC}$ bivalent genes at indicated phases of the cell cycle. Binding relative to the average is presented. (H) Genome browser view of Ezh2 ChIP-seq data across cell cycle at the Hoxd gene cluster. Suz12 binding was analyzed using published data (19). (I and J) Histogram showing enrichment of Ezh2 (I) or H3K27me3 (J) at PRC2 target promoter regions (Dach1, Sox7, Ascl1, Pax3, Msx1, and Nkx2-2) in $\mathrm{G}_{1}$ (black), S (gray), and $\mathrm{G}_{2}-\mathrm{M}$ (red) assayed by ChIP-qPCR. Active (Oct4, Nanog, and Hprt1) and hypermethylated (Myf5 and $\left.\lambda-5\right)$ gene promoters were used as negative controls. Means \pm SEM of three $(\mathrm{I})$ or four $(J)$ experiments is shown. $(E, I$, and $J)$ Asterisk $\left({ }^{*}\right)$ marks statistically significant differences. 
a list of high confidence Polycomb target bivalent genes [High confidence (HC) bivalent, $n=1678$ ] (Fig. 1B). As controls, we used transcriptionally active $(n=1557)$ and hypermethylated $(n=656)$ genes that are not targeted by PRC2 (see Methods and table S3). Heatmap analysis of Ezh2 binding to HC bivalent genes showed that recruitment of Ezh2 was increased as cells exit $\mathrm{G}_{1}$ and transit into $\mathrm{S}$ and $\mathrm{G}_{2}-\mathrm{M}$ phases (Fig. 1C). Comparison of Ezh2 binding at $\mathrm{HC}$ bivalent gene promoters showed that, although Ezh2 accumulates around the transcription start site (TSS) of bivalent genes at all cell cycle phases, the amount of Ezh2 bound gradually increases as cells exit $\mathrm{G}_{1}$ phase and transit through the cell cycle (Fig. 1, D and E, and fig. S1, B and C). Recruitment of Ezh2 in $\mathrm{G}_{1}$ phase appeared weak compared to $\mathrm{G}_{2}-\mathrm{M}$ (Fig. 1, D and E), but it was evident when compared to hypermethylated promoters known to be devoid of PRC2 (Fig. 1F and fig. S1D). Analysis of Ezh2 binding at individual promoters revealed a very consistent and gradual accumulation of Ezh2 during $\mathrm{S}$ and $\mathrm{G}_{2}-\mathrm{M}$ phases in most (1576 of 1677; 93.9\%) HC bivalent gene promoters (see clusters I and II in Fig. 1G and fig. S1E) including the archetypical Hoxd gene cluster (Fig. 1H). These observations were confirmed by ChIP-quantitative polymerase chain reaction (qPCR) for Ezh2 and analysis of a subset of well-characterized (18) PRC2 target promoters (Fig. 1I). Increased binding of Ezh2 during $S$ and $\mathrm{G}_{2}-\mathrm{M}$ phases was particularly obvious at bivalent promoters, but it could also be detected at bivalent gene bodies and other Ezh2-bound genomic regions (fig. S1F). Enhanced recruitment of Ezh2 upon $\mathrm{G}_{1}$ phase exit resulted in concomitant accumulation of $\mathrm{H} 3 \mathrm{~K} 27 \mathrm{me} 3$ at bivalent promoters during $\mathrm{S}$ and $\mathrm{G}_{2}-\mathrm{M}$ phases (Fig. 1J). Thus, we concluded that binding of Ezh2 to target promoters is markedly enhanced upon $\mathrm{G}_{1}$ phase exit in mESCs.

\section{Inverse binding patterns of Jarid2 and EPOP across cell cycle} We next asked whether accumulation of Ezh2 at bivalent promoters during $\mathrm{S}$ and $\mathrm{G}_{2}-\mathrm{M}$ phases reflected increased binding of PRC2.1, PRC2.2, or both. ChIP-seq analysis of Jarid2 binding in cell cyclesorted FUCCI-mESCs demonstrated that recruitment of Jarid2 to the promoter region of $\mathrm{HC}$ bivalent genes was augmented in $\mathrm{S}$ and $G_{2}-M$ phases compared to $G_{1}$ phase (Fig. 2, A and B, and fig. S2, $A$ and $B$ ). Increased recruitment of Jarid2 to target genes in $S$ and $\mathrm{G}_{2}-\mathrm{M}$ phases was evident but quantitatively less accused than changes found in binding of Ezh2 across cell cycle (Fig. 1D). Notwithstanding, clustering analysis showed a very consistent tendency to accumulate Jarid2 in $\mathrm{G}_{2}-\mathrm{M}$ at individual $\mathrm{HC}$ bivalent genes (1404 of 1677; 83.7\%) (see clusters I and II in Fig. 2C). Jarid2 was bound to most of the Ezh2-bound HC promoters in $\mathrm{G}_{2}-\mathrm{M}$ (1188 of 1262; 94\%) (fig. S2C), and binding of Jarid2 and Ezh2 around the TSS of $\mathrm{HC}$ bivalent gene promoters in $\mathrm{G}_{2}$ - $\mathrm{M}$ displayed concordant distributions (Fig. 2D). Correlation analysis demonstrated that accumulation of Jarid 2 at target genes in $\mathrm{S}$ and $\mathrm{G}_{2}-\mathrm{M}$ phases correlates with increased recruitment of Ezh2 to the same promoter regions (Fig. 2E). Coordinated recruitment of Jarid2 and Ezh2 to target genes upon $\mathrm{G}_{1}$ phase exit was also observed at individual candidate regions (i.e., gene Adra2c) (Fig. 2F). While increased binding of Jarid2 to HC bivalent promoters was clear in $\mathrm{G}_{2}-\mathrm{M}$ compared to $\mathrm{G}_{1}$ phase (Fig. $2 \mathrm{C}$ ), changes in recruitment of Jarid2 in $\mathrm{S}$ phase were less homogeneous. Most of
A

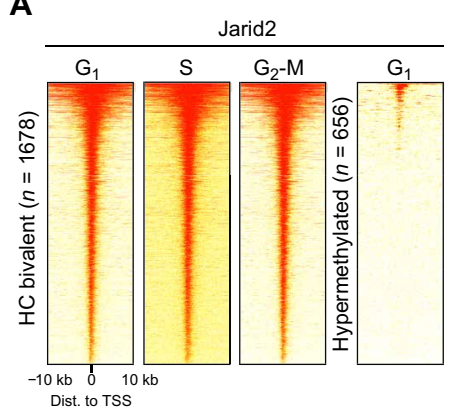

D

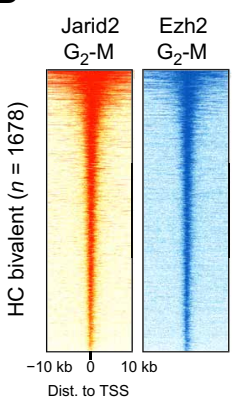

E
B
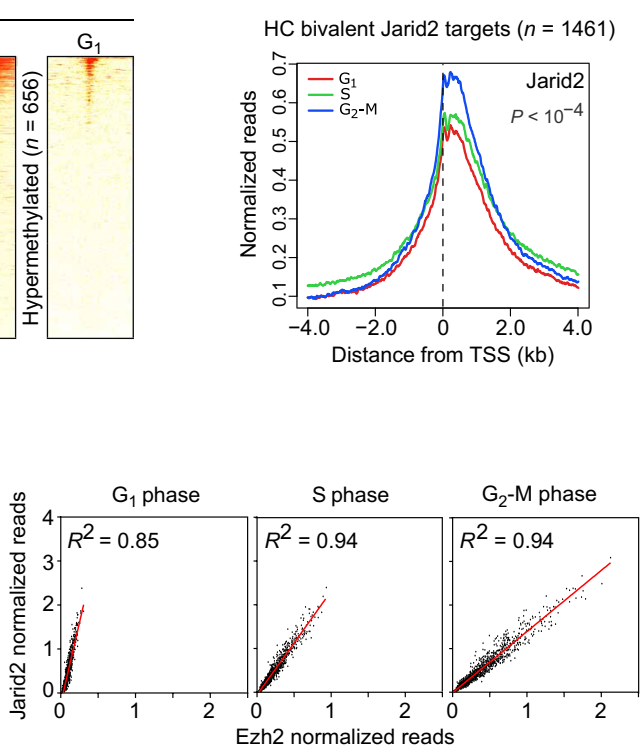

C

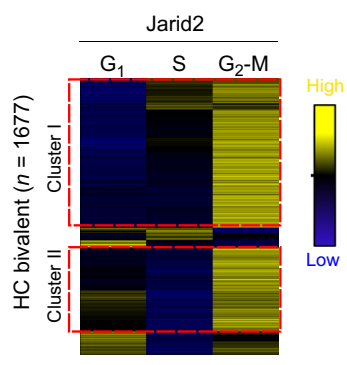

$\mathbf{F}$

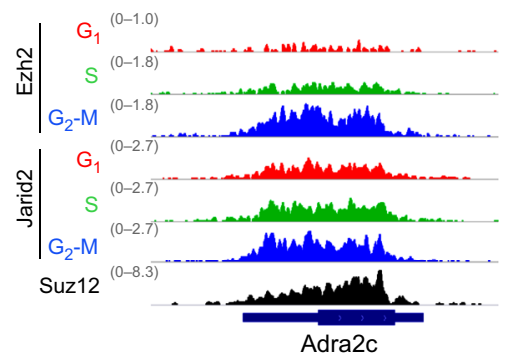

Fig. 2. Binding of Jarid2 to target promoters increases during $\mathbf{S}$ and $\mathbf{G}_{\mathbf{2}}-\mathbf{M}$ phases of the cell cycle. (A) Heatmaps of normalized ChIP-seq reads showing the binding of Jarid2 around the TSS of HC bivalent promoters at different cell cycle phases. Heatmap of hypermethylated promoters is shown as a negative control. (B) Average binding profile of Jarid2 around the TSS of HC bivalent promoters in $\mathrm{G}_{1}$ (red), $\mathrm{S}$ (green), and $\mathrm{G}_{2}-\mathrm{M}$ (blue). (C) Hierarchical clustering analysis of binding of Jarid2 to the promoter region ( -0.5 to $+1.5 \mathrm{~kb}$ relative to TSS) of $\mathrm{HC}$ bivalent genes at indicated phases of the cell cycle. Binding relative to the average is presented. (D) Heatmaps comparing the binding of Jarid2 and Ezh2 around the TSS of $\mathrm{HC}$ bivalent promoters in $\mathrm{G}_{2}-\mathrm{M}$. (E) Linear regression analysis showing the correlation between the binding signals of Jarid 2 and Ezh2 at HC bivalent promoters ( -0.5 to $+1.5 \mathrm{~kb}$ relative to TSS) at indicated cell cycle phases. (F) Genome browser view of Ezh2 and Jarid 2 binding across cell cycle at the Adra2c bivalent gene. Suz12 binding was analyzed using published data (19). 
the HC bivalent genes (cluster I, 899 genes; 64\%) showed increased binding of Jarid2 in $S$ phase compared to $G_{1}$ phase; however, a smaller proportion of genes (cluster II, 505 genes; 36\%) showed reduced binding of Jarid2 in this cell cycle phase (Fig. 2C). This pattern is in contrast with the homogeneous increase of Ezh2 binding at $\mathrm{HC}$ bivalent promoters in S phase (Fig. 1G) and suggests that recruitment of Ezh2 to target genes in S phase might be Jarid2 independent for this subset of bivalent genes (cluster II).

We next analyzed binding of the PRC2.1 subunit EPOP. In stark contrast to the binding pattern observed for Ezh2 and Jarid2, binding of EPOP around the TSS of HC bivalent genes was reduced in cells in $\mathrm{G}_{2}-\mathrm{M}$ (Fig. 3, A to C, and fig. S3, A and B). Clustering analysis showed that increased binding of EPOP in $\mathrm{G}_{1}$ phase compared to $\mathrm{G}_{2}-\mathrm{M}$ can be observed in most (1426 of 1677; 85\%) bivalent gene promoters (see cluster I in fig. S3C). Increased recruitment of EPOP to target promoters in $\mathrm{G}_{1}$ phase was also observed by ChIP-qPCR for a representative set of PRC2 target promoters (Fig. 3D). We next addressed whether increased binding of EPOP in $\mathrm{G}_{1}$ phase led to augmented recruitment of EloB in this cell cycle phase. As expected, ChIP-seq analysis showed that EloB is recruited to $\mathrm{HC}$ bivalent genes more profoundly in $G_{1}$ phase compared to $S$ and $G_{2}-M$ phases in average (Fig. 3, $\mathrm{E}$ to $\mathrm{G}$, and fig. S3, D and E) and individual gene (fig. S3F) analyses. Global levels of Ezh2, Jarid2, and EPOP across cell cycle were unchanged, indicating that differential recruitment to target genes is regulated by changes in protein interactions rather than changes in protein abundance (Fig. 3H and fig. S3, G and H). Together, these results demonstrate that Jarid2 and Ezh2 recruitment is increased during $\mathrm{S}$ and $\mathrm{G}_{2}-\mathrm{M}$ phases, while EPOP and EloB are preferentially bound to chromatin in $G_{1}$ phase. This indicates that PRC2.1 complex is preferentially recruited to target promoters during $G_{1}$ phase while PRC2.2 complex is favored during $S$ and $\mathrm{G}_{2}-\mathrm{M}$ phases.

\section{RNA synthesis is reduced and Ser $^{5}$-RNAPII is accumulated at PRC2 target genes during $S$ and $G_{2}-M$ phase}

We next questioned whether changes in recruitment of PRC2 subunits across cell cycle had functional consequences in the transcriptional regulation of target genes. To analyze low-level RNA transcription typically found at bivalent promoters, we used 4-thiouridine (4sU) tagging followed by high-throughput sequencing ( $4 \mathrm{~s} \mathrm{U}$-seq). $4 \mathrm{~s} \mathrm{U}$-seq permits the analysis of newly transcribed RNA (fig. S4A) $(26,27)$ and thus allowed us to minimize contamination of RNA molecules produced in preceding phases of the cell cycle. We found increased production of RNA in $\mathrm{G}_{1}$ phase compared to $\mathrm{S}-\mathrm{G}_{2}-\mathrm{M}$ at $\mathrm{HC}$ bivalent genes but not at promoters of active genes (Fig. 4, A and B, and fig. S4, B and C). Of 1655 HC bivalent genes, 974 genes showed differences in RNA production between $\mathrm{G}_{1}$ and $\mathrm{G}_{2}-\mathrm{M}$. Among these, most of them $(715 ; 73.4 \%)$ were down-regulated in $\mathrm{G}_{2}-\mathrm{M}$ compared to $\mathrm{G}_{1}$ phase (fig. S4D), revealing a consistent tendency of bivalent genes to be more strictly repressed during $S$ and $G_{2}-M$ phases than in $G_{1}$ phase. In agreement, analysis of individual candidate genes confirmed that bivalent promoters (i.e., Nes) are overtly repressed in $\mathrm{S}$ and $\mathrm{G}_{2}-\mathrm{M}$ phases

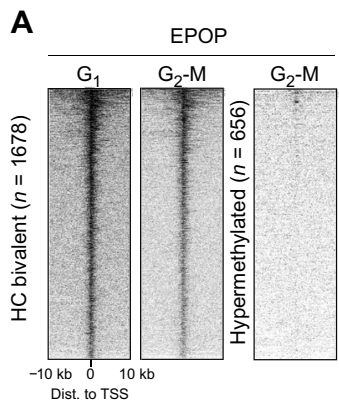

B

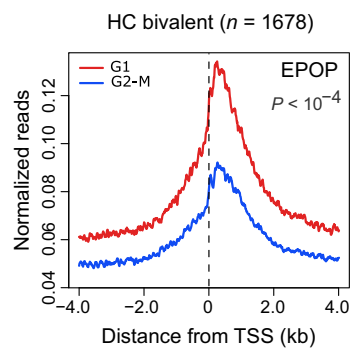

$\mathbf{F}$

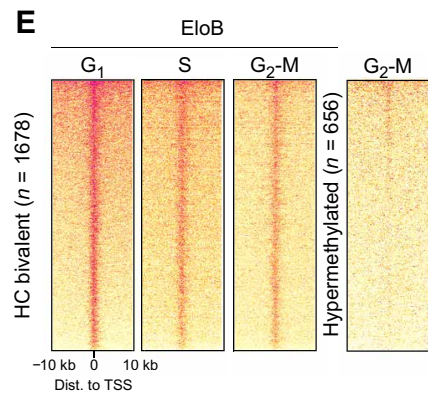

C

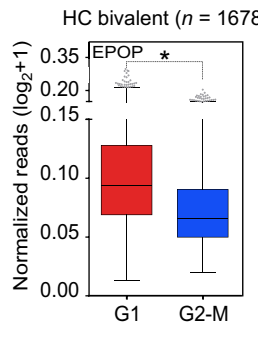

G

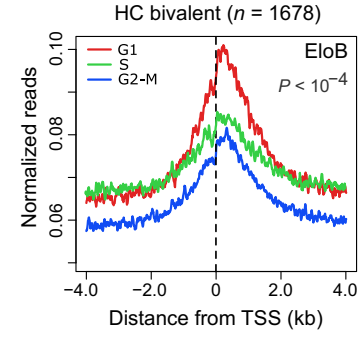

D

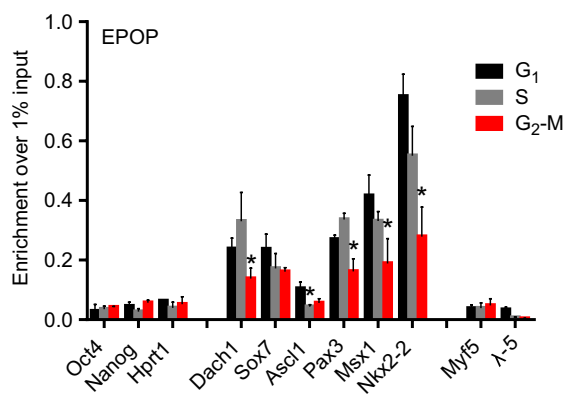

$\mathrm{H}$

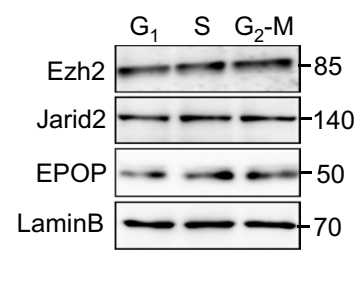

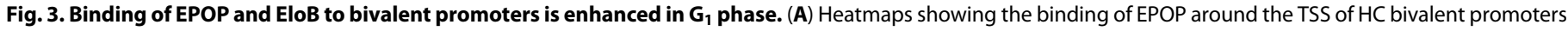

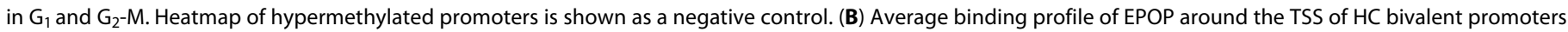

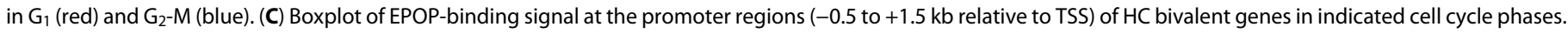

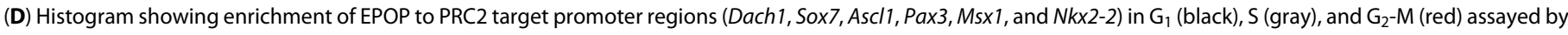

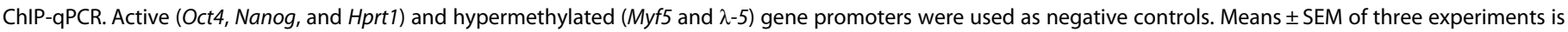

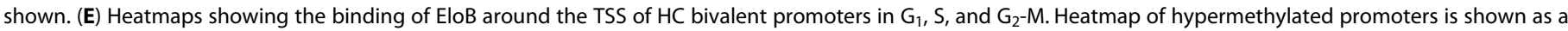

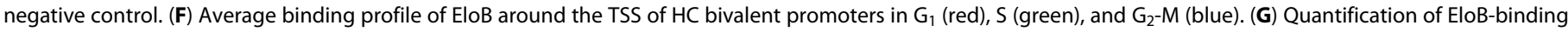

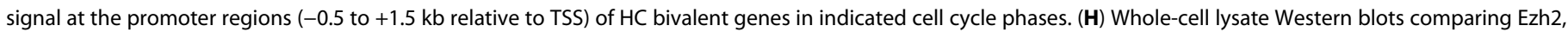
Jarid2 and EPOP protein levels in $G_{1}, S$, and $G_{2}-M$. Lamin B was used as a loading control. (C, D, and $G$ ) Asterisk (*) marks statistically significant differences. 
A

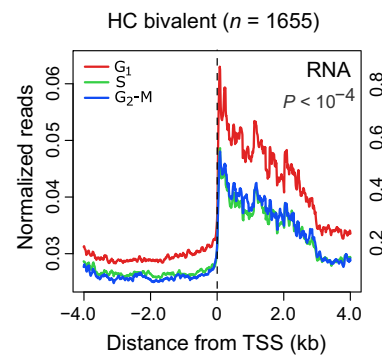

D

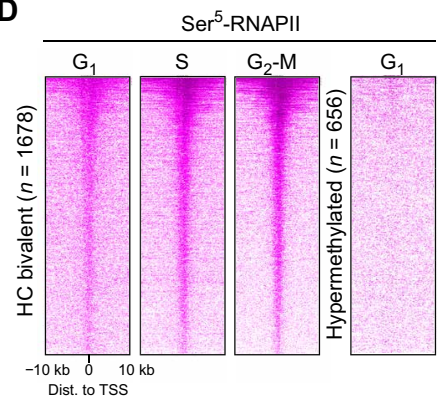

H
B

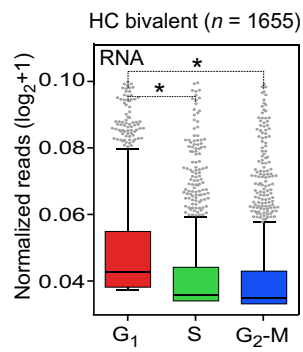

C

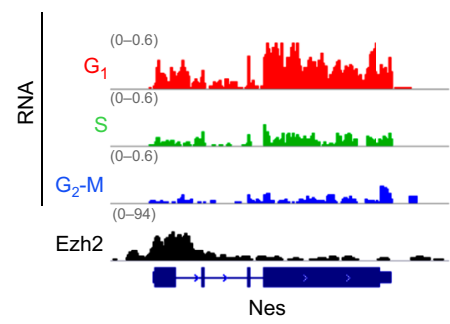

E

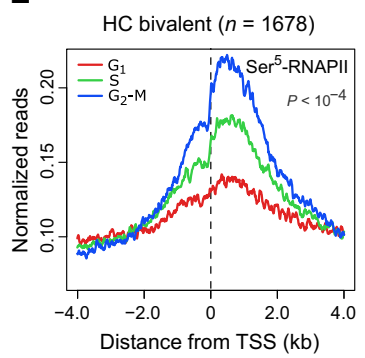

F

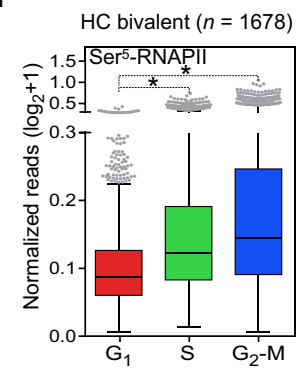

G

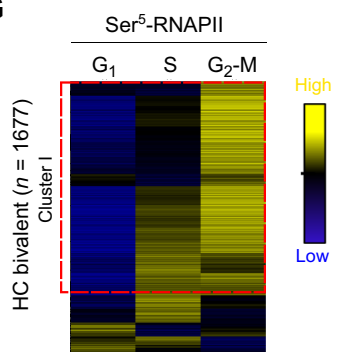

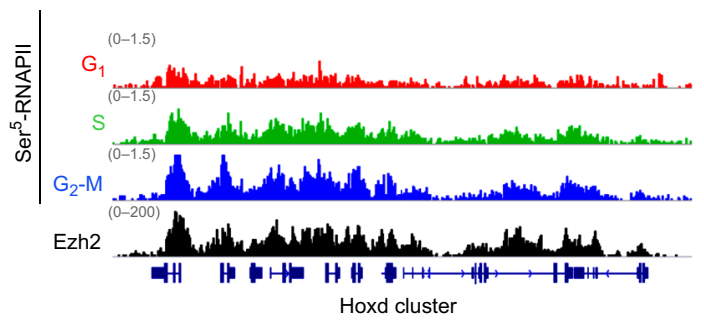

J

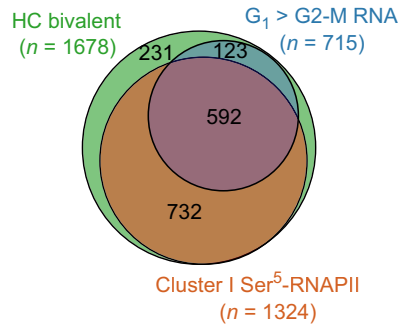

K

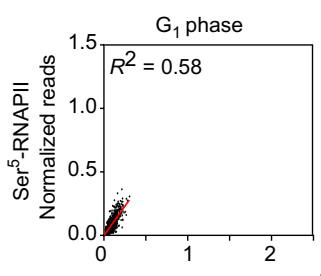

I

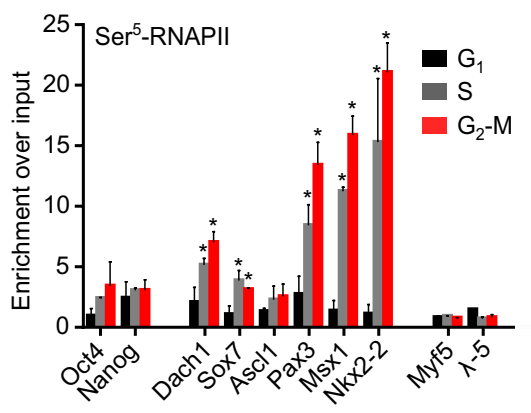

L

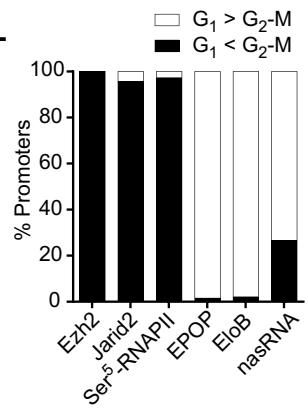

Fig. 4. RNA synthesis is down-regulated and Ser-RNAPII is accumulated at PRC2 target promoters during S and $\mathrm{G}_{2}-\mathrm{M}^{5}$ phase. (A) Average RNA production from HC bivalent (left) and active (right) promoters in $\mathrm{G}_{1}$ (red), $\mathrm{S}$ (green), and $\mathrm{G}_{2}-\mathrm{M}$ (blue). (B) Boxplot comparing $4 \mathrm{~s} \mathrm{U}$-seq reads mapped to the proximal promoter region (TSS to $+3 \mathrm{~Kb}$ ) of HC bivalent genes in indicated cell cycle phases. (C) Genome browser view of RNA synthesis at indicated cell cycle phases at the bivalent gene Nes. Ezh2 binding was

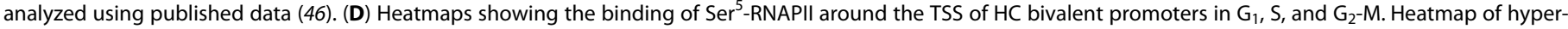
methylated promoters is shown as a negative control. (E) Average binding profile of Ser ${ }^{5}$-RNAPIl around the TSS of HC bivalent gene promoters in $\mathrm{G}_{1}$ (red), $\mathrm{S}$ (green), and $\mathrm{G}_{2}-\mathrm{M}$ (blue). (F) Quantification of Ser ${ }^{5}$-RNAPII-binding signal at the promoter regions ( -0.5 to $+1.5 \mathrm{~kb}$ relative to TSS) of $\mathrm{HC}$ bivalent genes in indicated cell cycle phases. (G) Hierarchical clustering analysis of binding of Ser ${ }^{5}$-RNAPIl to the promoter region ( -0.5 to $+1.5 \mathrm{~kb}$ relative to TSS) of HC bivalent genes at indicated phases of the cell cycle. Binding relative to the average is presented. (H) Genome browser view of the binding of Ser ${ }^{5}$-RNAPIl across cell cycle at the Hoxd gene cluster. Ezh2 binding was analyzed using published data (46). (I) Analysis by ChIP-qPCR of Ser ${ }_{5}$-RNAPII binding at PRC2 target promoter regions (Dach1, Sox7, Ascl1, Pax3, Msx1, and Nkx2-2) in G 1 (black), $S$ (gray), and $\mathrm{G}_{2}-\mathrm{M}$ (red) assayed by ChIP-qPCR. Active (Oct4 and Nanog) and hypermethylated (Myf5 and $\lambda-5$ ) gene promoters were used as controls. Means \pm SEM of three experiments is shown. ( $J$ ) Venn diagram showing the overlap between $\mathrm{HC}$ bivalent genes overtly repressed in $\mathrm{G}_{2}-\mathrm{M}(\mathrm{FC}>1.5)$ and genes displaying accumulation of Ser-RNAPII at their promoter region in $\mathrm{G}_{2}-\mathrm{M}$ (cluster I in Fig. $3 \mathrm{G}$ ). (K) Linear regression analysis of the binding signals of Ezh2 and Ser ${ }^{5}$-RNAPII at HC bivalent promoters $\left(-0.5\right.$ to $+1.5 \mathrm{~kb}$ relative to TSS) at indicated cell cycle phases. (L) Histogram displaying the percentage of genes showing changes $\left(G_{1}>G_{2}-M\right.$ or $\left.G_{1}<G_{2}-M\right)$ of binding for Ezh2 (FC > 2), Jarid2 (FC > 1.3), Ser ${ }^{5}$-RNAPII (FC > 2), EPOP $(F C>1.5)$, EloB $(F C>1.5)$, and RNA production (FC > 1.5) during cell cycle transition. Genes that showed no difference between analyzed phases were excluded to calculate the percentage. (B, F, and I) Asterisk (*) marks statistically significant differences. FC, fold change. 
(Fig. 4C). The level of RNA synthesized from bivalent promoters in $G_{1}$ phase was still very low compared to the level of RNA produced at active promoters (compare scale of $y$ axis in HC bivalent and Active plots; Fig. 4A), indicating that transient alleviation of PRC2 repression in $G_{1}$ results in increased leaky transcription rather than full activation of bivalent genes.

To address whether recruitment of Jarid2-Ezh2 and firmer repression of bivalent genes during $\mathrm{S}-\mathrm{G}_{2}-\mathrm{M}$ were associated with changes in the activity of RNAPII, we analyzed binding of Ser ${ }^{5}$-RNAPII, typically associated with transcriptionally pausing and gene poising of bivalent genes in mESCs (28). We found augmented accumulation of Ser $^{5}$-RNAPII around the TSS of HC bivalent genes in S and $\mathrm{G}_{2}-\mathrm{M}$ phases as compared to $\mathrm{G}_{1}$ phase (Fig. 4 , D to F, and fig. S4, E and $F$ ). Increased binding of Ser ${ }^{5}$-RNAPII was evident for most bivalent promoters (1324 of 1677; 78.9\%) genes (see cluster I in Fig. 4G) and at individual candidate bivalent genomic domains (i.e., Hoxd gene cluster) (Fig. 4H). ChIP-qPCR analysis of a subset of PRC2 target genes further confirmed gradual accumulation of Ser ${ }^{5}$-RNAPII during $S$ and $\mathrm{G}_{2}-\mathrm{M}$ phases compared to $\mathrm{G}_{1}$ phase (Fig. $4 \mathrm{I}$ ). Most of $\mathrm{HC}$ bivalent genes $(592$ of $715 ; 82.7 \%)$ that showed reduced RNA synthesis in $\mathrm{G}_{2}-\mathrm{M}$ displayed accumulation of $\mathrm{Ser}^{5}$-RNAPII at their promoter region (Fig. 4J), suggesting that reduced production of RNA is coupled to RNAPII pausing at the promoters of bivalent genes during $S$ and $\mathrm{G}_{2}-\mathrm{M}$ phases. Increased recruitment of Ezh2 (or Jarid2) during $S$ and $\mathrm{G}_{2}-\mathrm{M}$ phases correlated with accumulation of $\mathrm{Ser}^{5}$ RNAPII at target promoters at all phases of the cell cycle, and it became more evident during $\mathrm{S}$ and $\mathrm{G}_{2}-\mathrm{M}$ phases (Fig. $4 \mathrm{~K}$ and fig. $\mathrm{S} 4 \mathrm{G}$ ). Together (Fig. $4 \mathrm{~L}$ and fig. $\mathrm{S} 4 \mathrm{H}$ ), these observations indicate that increased recruitment of Jarid2-Ezh2 to target genes is associated with reduced binding of EPOP and EloB, pausing of transcription by RNAPII, and reduced production of leaky RNA during $S$ and $\mathrm{G}_{2}-\mathrm{M}$ phases.

\section{Cell cycle-dependent regulation of PRC2 is more evident at the promoter of developmental transcription factors}

We reasoned that, because cell cycle-dependent regulation of bivalent genes involved changes in recruitment of Jarid2, Ezh2, EPOP, EloB, and Ser ${ }^{5}$-RNAPII, bivalent genes that are common targets of these proteins in asynchronous mESCs might display more accused regulation across cell cycle. Notably, we found that a set of 390 bivalent genes cobound by these factors (common target genes) (Fig. 5A) is very significantly enriched for transcription factors and DNA binding proteins (162 of 390 genes; $P=7.6 \times 10^{-94}$ ), in contrast to the remaining 991 genes that are enriched for protein binding and transmembrane transporters (Fig. 5B). Common target genes included key pioneering factors involved in mesoderm, ectoderm, and endoderm differentiation (fig. S5A), suggesting that cell cycledependent regulation of Polycomb recruitment modulates differentiation to the three germ layers. In fitting, bivalent genes that showed more accused cell cycle-dependent changes in PRC2 binding were also enriched in a similar subset of transcription factors (fig. S5, B to E). Comparative analysis of PRC2 binding revealed that common targets are more profoundly bound by PRC2 subunits (Ezh2, Jarid2, and EPOP) and Ser ${ }^{5}$-RNAPII than remaining genes and that their differential recruitment of PRC2 subunits, $\mathrm{Ser}^{5}$-RNAPII, and RNA production across cell cycle are more accused (Fig. 5C and fig. S6, A and B). In agreement, analysis using published data of PRC2 binding in asynchronous populations of mESCs showed that recruitment of Ezh2, Jarid2, EPOP, and EloB, as well as
Eed, Suz12, Mtf2, and H3K27me3 was higher at the promoters of common targets than at the promoters of remaining genes (fig. S6C). In contrast, common targets were not enriched for trithorax protein MLL2 and H3K4me3 (fig. S6C). Together, these results indicate that the promoter regions of transcription factors that regulate cell differentiation recruit higher levels of PRC2 subunits that are prominently regulated across cell cycle.

\section{Cell cycle-dependent regulation of PRC2 is hindered in Jarid 2 -I- mESCs}

We next tested how the lack of the PRC2-recruiter Jarid2 affected the cell cycle-dependent regulation of PRC2. We derived FUCCIJarid2 -/- by introducing the FUCCI reporter system into previously derived Jarid2 -/- mESCs (fig. S7A) (20). Jarid2-depleted mESCs have been reported to display reduced binding of core PRC2 subunits and Ser $^{5}$-RNAPII $(18,20)$ to bivalent promoters, but they show unchanged levels of EPOP binding at target genes (23). In fitting, depletion of Jarid2 hinders accumulation of $\mathrm{H} 3 \mathrm{~K} 27 \mathrm{me} 3$ at target promoters during $S$ and $\mathrm{G}_{2}-\mathrm{M}$ phases (Fig. $6 \mathrm{~A}$ and fig. $\mathrm{S} 7, \mathrm{~B}$ and $\mathrm{C}$ ) where binding of Ezh 2 and $\mathrm{H} 3 \mathrm{~K} 27 \mathrm{me} 3$ is more accused in wild-type cells (Fig. 1). Analysis of RNA expression and binding of $\mathrm{Ser}^{5}$ RNAPII revealed that depletion of Jarid2 and concomitant decrease in $\mathrm{H} 3 \mathrm{~K} 27 \mathrm{me} 3$ at bivalent promoters results in derepression of RNA synthesis and loss of Ser $^{5}$-RNAPII during $S$ and $\mathrm{G}_{2}-\mathrm{M}$ phases (Fig. 6, B and C, and fig. S7, D and E). Analysis by ChIP-qPCR further confirmed that accumulation of paused Ser $^{5}$-RNAPII at bivalent genes in $S$ and $G_{2}-M$ phases is visibly reduced in Jarid2 -/- compared to parental mESCs (Fig. 6D and fig. S7, F and G). Depletion of Jarid2 had no detectable effect on the level of H3K27me3, Ser ${ }^{5}$-RNAPII binding, or RNA synthesis in cells in $\mathrm{G}_{1}$ phase (Fig. $6 \mathrm{~B}$ and fig. S7B), suggesting that the function of Jarid2 and PRC2.2. might be specific of $S$ and $G_{2}-M$ phases and dispensable in $G_{1}$ phase. Overall, these results demonstrate that increased recruitment of Jarid2 and Ezh2 to bivalent genes during $S$ and $\mathrm{G}_{2}-\mathrm{M}$ phases results in enhanced $\mathrm{H} 3 \mathrm{~K} 27 \mathrm{me} 3$ deposition, pausing of RNAPII, and reduced production of RNA transcripts.

\section{DISCUSSION}

Our results show that recruitment of PRC2 complexes to target promoters is regulated across cell cycle and indicate that PRC2.1 complexes are preferentially recruited in $\mathrm{G}_{1}$ phase, while binding of PRC2.2 is favored in $\mathrm{S}$ and $\mathrm{G}_{2}-\mathrm{M}$ phases (Fig. 6E). This is supported by our ChIP-seq analysis revealing augmented binding of EPOP and EloB (part of PRC2.1) to target promoters in $\mathrm{G}_{1}$ phase as opposed to increased binding of Jarid2 (part of PRC2.2) during $S$ and $\mathrm{G}_{2}-\mathrm{M}$ phases. We found that binding of the catalytic subunit Ezh2 is markedly increased in $S$ and $G_{2}-M$ phases compared to $G_{1}$ phase, indicating that regulation across cell cycle is not exclusive of accessory subunits but is also happening for the core catalytic subunit of the complex. This is in fitting with previous reports, suggesting a cell cycle-dependent regulation of Ezh2 binding by CDK1 and CDK2 phosphorylation (29). Jarid2 activity is known to favor high levels of PRC2 binding (18-22), while EPOP activity promotes the opposite (23). Thus, reduced recruitment of Ezh2 in $G_{1}$ phase is probably a consequence of the accumulation of EPOP-PRC2 (PRC2.1) at the expense of Jarid2PRC2 (PRC2.2) complexes in this cell cycle phase. We showed that nascent RNA produced in $G_{1}$ phase is still in the range of leaky transcription rather than full activation of target genes, suggesting that 
A

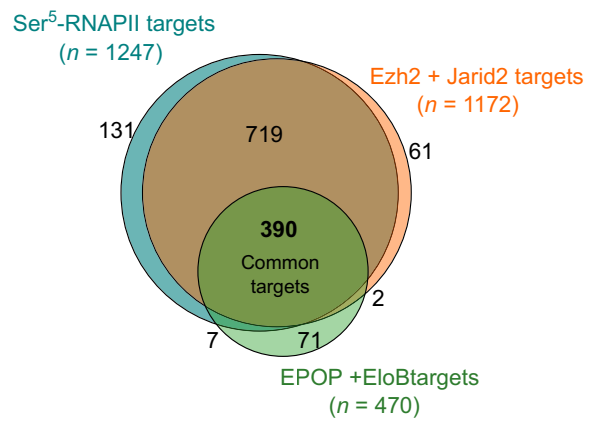

B

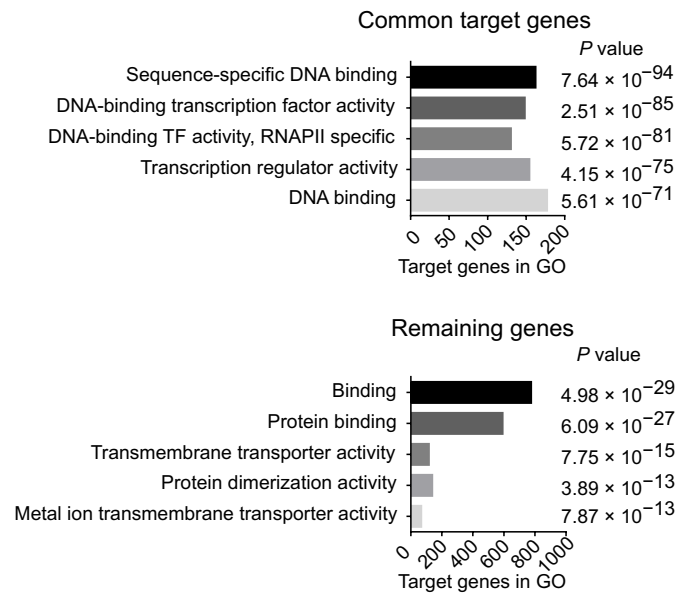

C
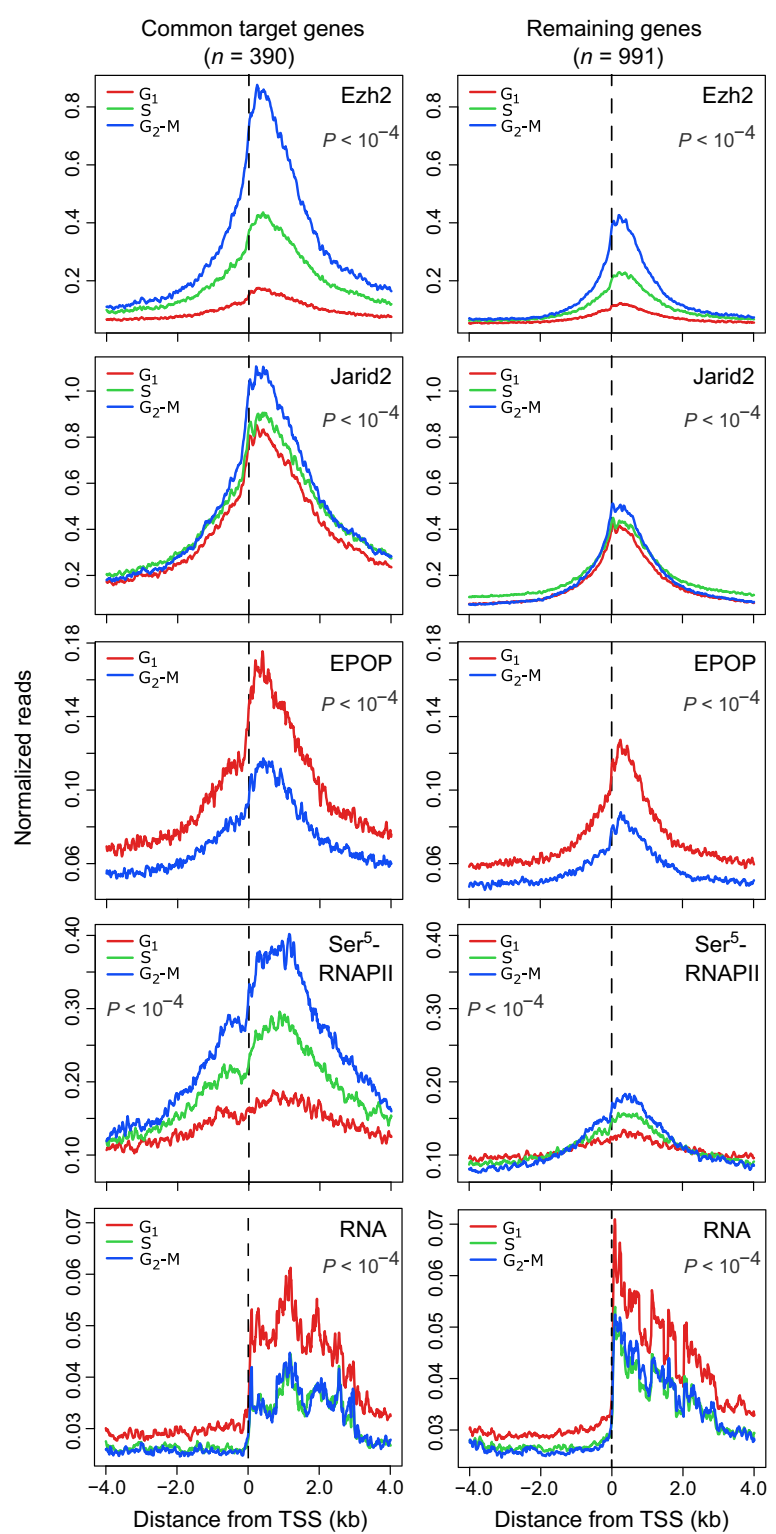

Fig. 5. Cell cycle-dependent regulation of PRC2 is more accused at the promoter of developmental transcription factors. (A) Venn diagram showing overlap between HC bivalent genes that are targets of Ser ${ }^{5}$-RNAPII, Ezh2, Jarid2, EPOP, and EloB in asynchronous populations using published (23,36) and our (Jarid2) datasets. (B) Gene Ontology (GO) analysis of common target and remaining genes. Bars represent the number of genes that fall into indicated $\mathrm{GO}$ categories. $P$ value is shown next to each category. (C) Average binding profile of Ezh2, Jarid2, EPOP, Ser ${ }^{5}-\mathrm{RNAPII}$, and RNA synthesis around the TSS of HC bivalent genes in $\mathrm{G}_{1}$ (red), $\mathrm{S}$ (green), and $\mathrm{G}_{2}-\mathrm{M}$ (blue) comparing common target and remaining HC bivalent genes (as defined in Fig. 5A).

although the amount of Ezh2 bound to promoters of bivalent genes in $G_{1}$ phase is lower than in $S$ and $G_{2}-M$ phases, it is probably enough to maintain substantial gene repression of target genes. Notwithstanding, repression of Ezh2 target genes in $\mathrm{G}_{1}$ phase might also be dependent on Ezh2-independent mechanisms (11), including the activity of Ezh1 or PRC1 complexes.

We found that recruitment of Jarid2-PRC2 (PRC2.2) during S and $\mathrm{G}_{2}-\mathrm{M}$ phases leads to more robust gene repression of target bivalent genes; reduced production of RNA coupled with increased binding of paused $\mathrm{Ser}^{5}$-RNAPII in $\mathrm{S}$ and $\mathrm{G}_{2}-\mathrm{M}$ phases that is lost upon Jarid2 depletion. These observations, together with the known role of EPOP in recruiting EloB and promoting leaky transcription at bivalent genes $(23,30)$, support that recruitment of EPOP-PRC2 (PRC2.1) to bivalent promoters in $\mathrm{G}_{1}$ phase favors a transcriptional permissive chromatin setup. Accumulation of $\mathrm{Ser}^{5}$-RNAPII is temporally coincident with recruitment of PRC2.2 during $S$ and $\mathrm{G}_{2}-\mathrm{M}$ phases. Because simultaneous binding of PRCs and Ser ${ }^{5}$-RNAPII at bivalent gene promoters is a key defining feature of transcriptional priming, our results highlight a previously unanticipated regulation of gene priming within the pluripotent cell cycle. In particular, our results demonstrate that gene priming is evident during $S$ and $\mathrm{G}_{2}-\mathrm{M}$ phases (high levels of Ezh2 and Ser ${ }^{5}$-RNAPII), but it is dismantled during 
A
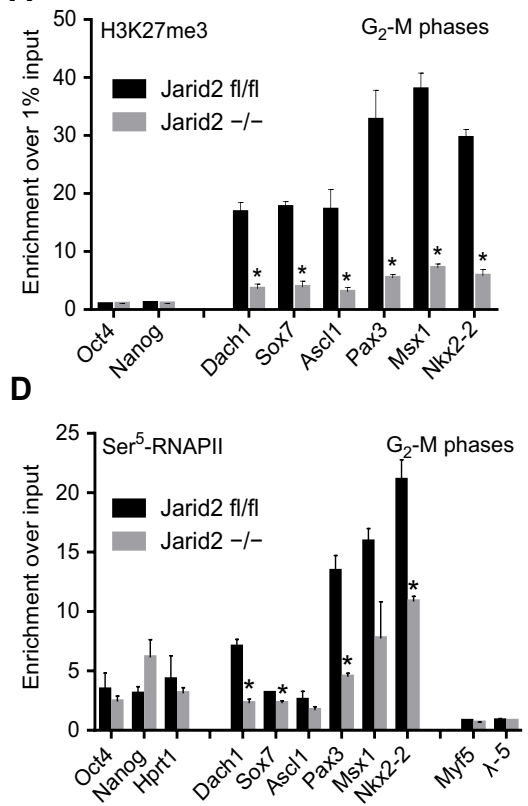

E

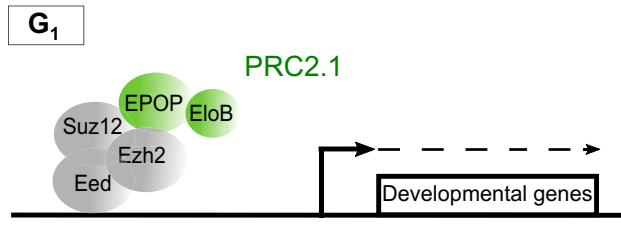

Differentiation prone

B
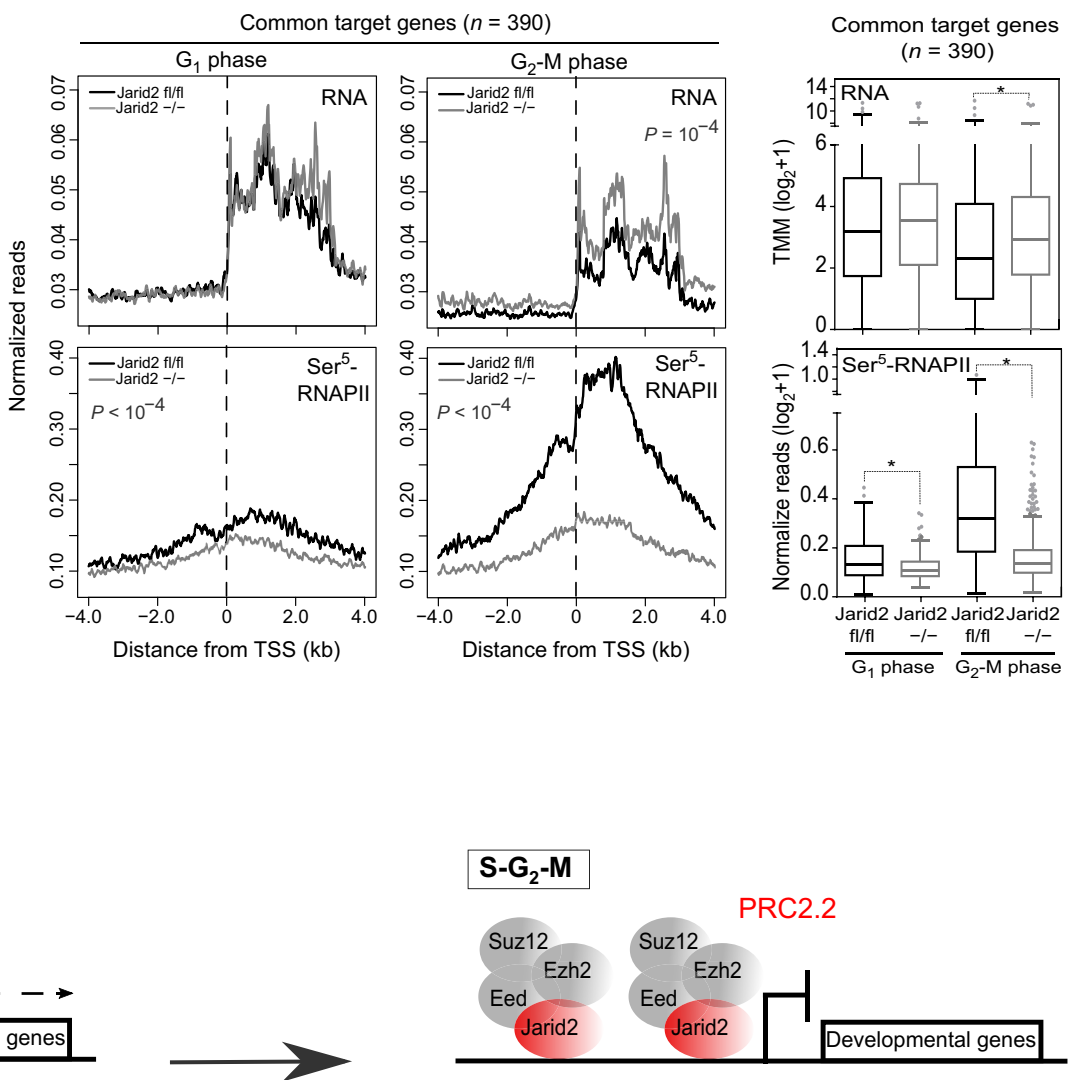

Differentiation resistant

Fig. 6. Jarid2 -I- mESCs display altered cell cycle-dependent regulation of bivalent genes. (A) Analysis by ChIP-qPCR comparing the enrichment of H3K27me3 at

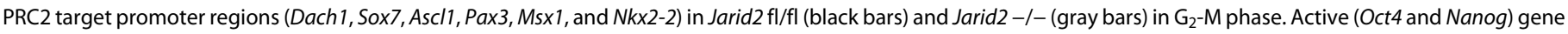
promoters were used as negative controls. Means \pm SEM of four experiments is shown. (B) Average RNA synthesis (top) and binding of Ser ${ }^{5}$-RNAPII (bottom) around the TSS of common target bivalent genes in $\mathrm{G}_{1}$ (left) and $\mathrm{G}_{2}-\mathrm{M}$ (right) in Jarid2 fl/fl (black lines) and Jarid2 -/- (gray lines) mESCs. (C) Quantification of RNA synthesis (top) and Ser ${ }^{5}$-RNAPII binding (bottom) in Jarid2 fl/fl and Jarid2 -/- cells in $\mathrm{G}_{1}$ and $\mathrm{G}_{2}-\mathrm{M}$ at common target genes. (D) Analysis by ChIP-qPCR comparing the binding of Ser ${ }^{5}$-RNAPII to PRC2 target promoter regions (Dach1, Sox7, Ascl1, Pax3, Msx1, and Nkx2-2) in Jarid2 fl/fl (black bars) and Jarid2 -/- (gray bars) in G2-M phase. Active (Oct4, Nanog, and $H$ prt) and hypermethylated (Myf5 and $\lambda-5)$ gene promoters were used as controls. Means \pm SEM of three experiments are shown. (E) Schematic diagram of observations described here. (A, C, and D) Asterisk (*) marks statistically significant differences.

$\mathrm{G}_{1}$ phase (low level of Ezh2 and Ser ${ }^{5}$-RNAPII), rather than being maintained until the exit of the pluripotent cell cycle.

Asynchronous populations of pluripotent cells display heterogenous expression of genes and cell differentiation ability $(2-4)$. This is partly because $\mathrm{G}_{1}$ phase cells display elevated expression of developmental regulators $(8)$, and they are more prone to activate lineagespecific genes in response to differentiation cues $(5,6)$. We found that $\mathrm{mESC}$ in $\mathrm{G}_{1}$ phase display a proactivation chromatin setup characterized by enhanced binding of the PRC2 activating subunits EPOP and EloB, together with reduced binding of Jarid2 and Ezh2. We showed that this leads to alleviation of transcriptional repression in $\mathrm{G}_{1}$ phase. In fitting, it has been reported that human ESCs display increased $\mathrm{H} 3 \mathrm{~K} 4 \mathrm{me} 3$ at the promoter of bivalent genes during $\mathrm{G}_{1}$ phase as compared to $\mathrm{S}$ and $\mathrm{G}_{2}-\mathrm{M}$ phases (31). Thus, given that derepression of PRC2 target genes is a critical early event during cell differentiation (32), transient alleviation of Polycomb repression in $G_{1}$ phase is a key observation to explain why pluripotent cells in $\mathrm{G}_{1}$ phase are more sensitive to differentiation signals.
Overall, in this study, we showed that Polycomb complexes subunit configuration is controlled by cell cycle-dependent mechanisms in mESCs and support that this type of regulation will be functionally relevant in the context of pluripotent cell differentiation. Our observations are in fitting with the established role of Polycomb as a regulator of pluripotent cell differentiation; however, to fully establish the relevance of cell cycle-mediated regulation of Polycomb function, future studies will need to address how the lack of Polycomb proteins at particular cell cycle phases affect cell differentiation. Because the general principles underlying Polycomb function are widely conserved from flies to humans (11), our discovery will probably be relevant for other model systems in which the regulation of gene expression by Polycomb needs to be coordinated with DNA replication and cell division, including adult stem cells and tumor cells (33). In addition, PRCs can also regulate gene activity in somatic $\mathrm{G}_{1}$ phase-arrested cells (33) and thus, in the future, it will be interesting to see to what extent differences in the regulation by Polycomb proteins in different model systems are a consequence of their different cell cycle configurations. 


\section{METHODS}

\section{ESCs growth, FUCCl, and flow cytometry}

Stable FUCCI mES cell lines (background 129/Sv/C57BL/C6) were generated for parental and Jarid2 knockout mESCs (20) by transfecting the ES-FUCCI plasmid (Addgene repository no. 62451) (34). mESCs expressing mCherry:hCdt and Citrine:Geminin were cultured in 5\% $\mathrm{CO}_{2}$ at $37^{\circ} \mathrm{C}$ on $0.1 \%$ gelatin-coated dishes in Dulbecco's modified Eagle's medium knockout (Gibco) media supplemented with $10 \%$ fetal calf serum (FCS), leukemia-inhibiting factor (LIF), penicillin/ streptomycin (Gibco), L-glutamine (Gibco), 2-mercaptoethanol (Gibco), and hygromycin B (InvivoGen), as described previously (35). Upon trypsinization and resuspension in sorting buffer [phosphatebuffered saline (PBS), 2\% FCS, 2 mM EDTA, and LIF] at $4^{\circ} \mathrm{C}$, FUCCImESCs were cell sorted in an Aria Fusion flow cytometer equipped with 488- and 561-mm lasers to discriminate cells expressing citrine $(516 \mathrm{~nm} / 529 \mathrm{~nm})$ and mCherry $(587 \mathrm{~nm} / 610 \mathrm{~nm})$. Sorted cells were counted and 1 million cells were used typically for downstream genome-wide analysis. Purity and cell cycle profile of sorted cell populations were routinely checked by propidium iodide staining, followed by flow cytometry. While $G_{1}$ and $G_{2}-M$ fractions were highly enriched for $G_{1}$ and $G_{2}-M$ cells, respectively, $S$ fraction was composed by less homogeneous cell populations; typically, $15 \%$ in $\mathrm{G}_{1}, 55 \%$ in $\mathrm{S}$, and $30 \%$ in $\mathrm{G}_{2}-\mathrm{M}$ (table $\mathrm{S} 1$ ).

\section{Gene promoter classification}

The list of bivalent genes (promoter positive for $\mathrm{H} 3 \mathrm{~K} 4 \mathrm{me} 3$ and H3K27me3) (3753 genes) was described previously (36). HC bivalent gene list (1678 genes) was obtained by extracting bivalent genes consistently described in three different studies (36-38). Active genes (1557 genes) were determined using published data (36): genes positive for H3K4me3, bound by phosphorylated (Ser ${ }^{5}$, Ser2, and Ser7), hypophosphorylated RNAPII (8WG16 antibody), with RNA expression higher than 20 Fragments Per Kilobase of transcript per Million mapped reads (FPKM) and negative for PRC2 binding (Ezh2, Suz12, and $\mathrm{H} 3 \mathrm{~K} 27 \mathrm{me} 3$ ). Hypermethylated promoters in mESCs (more than $80 \%$ CpG methylation) were identified using published bisulfite sequencing data (39) and cross-analyzed with published data (36) to identify hypermethylated promoters transcriptionally silent (less than 1 FPKM) and not bound by PRC2 (Ezh2, Suz12, and H3K27me3) (656 genes). See table S3 for complete gene lists.

\section{ChIP-qPCR and sequencing}

ChIP assays for H3K27me3, Ser ${ }^{5}$-RNAPII, Ezh2, Jarid2, and EPOP (table S4) were performed as described previously (36) with minor modifications: Typically, 1 million cell cycle-sorted cells were resuspended in $37^{\circ} \mathrm{C}$ complete media ( $200 \mu$ l per million cells) and incubated in a rotating platform for $12 \mathrm{~min}$ with $1 \%$ formaldehyde at room temperature. To stop the reaction, glycine was added to a final concentration of $125 \mathrm{mM}$. Swelling and sonication buffers (protease and phosphatase inhibitors supplemented) were used at $4^{\circ} \mathrm{C}$ in a proportion of $0.5 \mathrm{ml}$ per million cells. Ezh2, H3K27me3, Jarid2, and EPOP ChIPs were carried without using bridge antibody. Chromatin and antibody were incubated in a rotating wheel at $4^{\circ} \mathrm{C}$ overnight. Protein G magnetic beads (Dynabeads, Invitrogen) were then added and incubated for 5 hours. Washes were carried out for $5 \mathrm{~min}$ at $4^{\circ} \mathrm{C}$ with $1 \mathrm{ml}$ of the following buffers: $1 \times$ sonication buffer, $1 \times$ wash buffer A [50 mM Hepes (pH 7.9), $500 \mathrm{mM} \mathrm{NaCl}, 1 \mathrm{mM}$ EDTA, 1\% Triton X-100, 0.1\% Na-deoxycholate, and 0.1\% SDS], $1 \times$ wash buffer B [20 mM tris (pH 8.0), 1 mM EDTA, $250 \mathrm{mM} \mathrm{LiCl,}$
0.5\% NP-40, and 0.5\% Na-deoxycholate], and $2 \times$ TE buffer $(\mathrm{pH} 8)$. ChIP of EloB was performed as above but adding a chromatin doublecross-link step as described in (23) with minor modifications: Cells were resuspended in $\mathrm{PBS}$ at $4^{\circ} \mathrm{C}$ after flow cytometry sorting and incubated with ChIP Cross-link Gold (Diagenode no. C01019027, $0.8 \mu \mathrm{l}$ in $200 \mu \mathrm{l}$ of PBS per 1 million cells) in a rotating platform for $30 \mathrm{~min}$ at room temperature. After one wash, step chromatin was cross-linked with $1 \%$ formaldehyde for $10 \mathrm{~min}$ at room temperature. ChIP-qPCR of Ezh2, H3K27me3, EPOP, and Ser ${ }^{5}$-RNAPII and quality control of all immunoprecipitated DNA samples were tested by qPCR using GoTaq qPCR Master Mix (Promega) with a QuantStudio 6 Flex Real-time PCR System (Applied Biosystems). Enrichment was calculated relative to $1 \%$ input for all ChIPs except for $\mathrm{Ser}^{5}$-RNAPII that was normalized by loading the same amount of DNA as described previously (36). Details of antibodies and primers used are available in table S5.

Libraries of immunoprecipitated DNA in Ezh2, Jarid2, EPOP, and EloB ChIP-seqs were generated from 1 to $5 \mathrm{ng}$ of starting DNA with the NEBNext Ultra DNA Library Prep kit for Illumina (no. 7370) according to the manufacturer's instructions at Centre for Genomic Regulation (CRG) Genomics Core Facility (Barcelona) and sequenced using HiSeq 2500 Illumina technology. Library of Ser ${ }^{5}$-RNAPII ChIP-seq was performed using the NextFlex ChIP-Seq kit (Bioo Scientific no. NOVA-5143-01), starting with 4 ng of immunoprecipitated DNA and sequenced at Centre for Genomics and Oncological Research (GENYO, Granada) using Illumina technology (NextSeq 500) according to the manufacturer's instructions. Twenty million to 30 million reads [50-base pair (bp) single reads] were obtained for each library.

Reads were aligned and quantified using STAR 2.5.2 (40) against GENCODE NCBI m37 (mm9) genome. SAMtools 1.3.1 (41) was used to discard alignments with a quality score $<200$ to remove multimapping reads. Last, we used BamCompare from deepTools suite (42) to create bigwig files with the signal normalized by reads per million (RPM) and against an input sample. Peak calling was performed with MACS2. Data mining of publicly available ChIP-seq datasets (Eed, Suz12, Ezh2, H3K27me3, Jarid2, EPOP, EloB, Mtf2, $\mathrm{Mll2}$, and $\mathrm{H} 3 \mathrm{~K} 4 \mathrm{me} 3$ ) were treated the same way. CoverageView (Coverage visualization package for $\mathrm{R}$. R package version 1.20.0.) was used to calculate coverage around TSS.

Average normalized reads (RPM) for a genomic window of -0.5 to $+1.5 \mathrm{~kb}$ relative to TSS for each analyzed promoter was calculated and represented as boxplots and were subjected to clustering using Cluster 3.0, followed by the Java TreeViewer software. $\log _{2}$ of binding values relative to the average were used. Average binding plots were generated by counting normalized reads every $10 \mathrm{bp}$. In heatmap analyses of reads density in ChIP-seq experiments, we $\log _{2}$-transformed RPMs and trimmed these values between the minimum 5th percentile and the maximum 95th percentile. To compare different samples, genes were ranked according to $\mathrm{G}_{2}-\mathrm{M}$ (Ezh2, Jarid2, and Ser ${ }^{5}$-RNAPII) or $\mathrm{G}_{1}$ phase (EPOP and EloB). Gene Ontology analysis was performed using the Gene Ontology knowledge database (geneontology.org).

\section{4sU-tagging sequencing}

$4 \mathrm{sU}$-seq experiments were carried out as described in (27) with minor modifications: Cells were treated with $4 \mathrm{sU}(500 \mu \mathrm{M})$ during 1 hour $37^{\circ} \mathrm{C}$ before trypsinization and flow cytometry sorting. One million sorted cells were resuspended in $500 \mu \mathrm{l}$ of TRIzol 
(Invitrogen). Isolated RNA was bioanalyzed (Agilent) and was subjected to qPCR analysis as quality control. 4sU-RNA and total RNA samples were retrotranscribed using the RevertAid RT Reverse Transcription kit (Thermo Fisher Scientific no. K1691), treated with deoxyribonuclease I (Thermo Fisher Scientific 18068015) and were subjected to qPCR using primers designed to specifically amplify unspliced RNA (contiguous exon-intron sequences) and total RNA (exon sequences). Strand-specific $4 \mathrm{sU}$-seq libraries were generated using $75 \mathrm{ng}$ of $4 \mathrm{sU}$-RNA and the NextFlex Rapid Directional RNA-seq kit (Bioo Scientific no. NOVA-5138-07) according to the manufacturer's instructions. Libraries were quantified by NanoDrop 2000 (Thermo Fisher Scientific) and bioanalyzed. Fifty million 75-bp paired-end reads per sample were sequenced using Illumina technology (NextSeq 500) at GENYO.

After quality control, we used SortMeRNA 2.1 software (43) to filter out ribosomal RNA reads. We aligned and quantified filtered reads with STAR 2.5.2 (40) using GENCODE NCBI m37 (mm9) as the reference genome. We used SAMtools 1.3.1 (41) to remove alignments with a quality score $<200$ to discard multimapping reads. Last, we used BamCompare from deepTools suite (42) to create bigwig files with normalized signal in RPM and with positive values for forward strand and negative values in reverse strand. To normalize gene expression values, we applied trimmed mean of $\mathrm{M}$ values (44) method with NOISeq package (45).

\section{Western blot analysis and cell fractionation}

Whole extracts were prepared for 1 million cells after flow cytometry sorting. Cells were pelleted and resuspended in $50 \mu \mathrm{l}$ of PBS and $50 \mu \mathrm{l}$ of $2 \times$ Laemmli buffer [0.1 M tris ( $\mathrm{pH} \mathrm{6.8),2 \%} \mathrm{SDS,} \mathrm{and}$ $5 \%$ glycerol] supplemented with protease and phosphatase inhibitors [1× EDTA-free inhibitor cocktail (Roche), $1 \mathrm{mM}$ phenylmethylsulfonyl fluoride, $5 \mathrm{mM} \mathrm{NaF}$, and $2 \mathrm{mM} \mathrm{Na} 3 \mathrm{VO} 4]$. Alternatively, 1 million cell cycle-sorted FUCCI wild-type cells subjected to cell fractionation as previously described in (23). Equivalent amount of cells was loaded for Western blots. Western blotting was carried out using standard procedures. Quantification of band intensity and normalization with LaminB was carried out using ImageJ.

\section{Statistical analysis}

Statistical analyses were carried out using R 3.5.1. In boxplots, whiskers denote the interval within $1.5 \times$ the interquartile range, and $P$ values were calculated using Mann-Whitney test (significant differences $P<0.0001)$. Average mapped reads around the TSS was carried out using analysis of variance (ANOVA), comparing all samples in a window of -0.5 to $+1.5 \mathrm{~kb}$ from TSS (significant differences $P<0.0001$ ). ChIP-qPCR statistical analysis was carried out for triplicates and using Student's $t$ test (significant differences $P<0.05$ ).

\section{SUPPLEMENTARY MATERIALS}

Supplementary material for this article is available at http://advances.sciencemag.org/cgi/ content/full/6/10/eaay4768/DC1

Fig. S1. Differential recruitment of the PRC2 catalytic subunit Ezh2 across cell cycle. Fig. S2. Cell cycle-dependent regulation of Jarid2.

Fig. S3. Binding of EPOP and EloB to bivalent promoters is regulated across cell cycle. Fig. S4. Transcriptional activity at $P R C 2$ target genes is attenuated during $S$ and $\mathrm{G}_{2}-\mathrm{M}$ phases. Fig. S5. Cell cycle-regulated PRC2 targets are enriched in developmental transcription factors. Fig. S6. PRC2 target promoters that are regulated across cell cycle display higher levels of PRC2 binding.

Fig. S7. Jarid2 -/- mESCs display abnormal regulation of H3K27me3, Ser-RNAPII, and RNA synthesis during $S$ phase of the cell cycle.
Table S1. Purity check of cell cycle-sorted mESCs used in ChIP-seq experiments. Table S2. Analysis of peaks detected in ChIP-seq experiments.

Table S3. List of genes used in this manuscript.

Table S4. ChIP-seq enrichment and 4sU-seq expression values of $\mathrm{HC}$ bivalent genes. Table S5. Table listing reagents and published datasets used in this manuscript.

View/request a protocol for this paper from Bio-protocol.

\section{REFERENCES AND NOTES}

1. M. Li, J.C. Izpisua Belmonte, Deconstructing the pluripotency gene regulatory network. Nat. Cell Biol. 20, 382-392 (2018).

2. R. M. Kumar, P. Cahan, A. K. Shalek, R. Satija, A. Jay DaleyKeyser, H. Li, J. Zhang, K. Pardee, D. Gennert, J. J. Trombetta, T. C. Ferrante, A. Regev, G. Q. Daley, J. J. Collins, Deconstructing transcriptional heterogeneity in pluripotent stem cells. Nature $\mathbf{5 1 6}$, 56-61 (2014).

3. A. M. Klein, L. Mazutis, I. Akartuna, N. Tallapragada, A. Veres, V. Li, L. Peshkin, D. A. Weitz, M. W. Kirschner, Droplet barcoding for single-cell transcriptomics applied to embryonic stem cells. Cell 161, 1187-1201 (2015).

4. T. S. Macfarlan, W. D. Gifford, S. Driscoll, K. Lettieri, H. M. Rowe, D. Bonanomi, A. Firth, O. Singer, D. Trono, S. L. Pfaff, Embryonic stem cell potency fluctuates with endogenous retrovirus activity. Nature $\mathbf{4 8 7}, 57-63$ (2012).

5. S. Pauklin, L. Vallier, The cell-cycle state of stem cells determines cell fate propensity. Cell 155, 135-147 (2013).

6. D. Coronado, M. Godet, P.-Y. Bourillot, Y. Tapponnier, A. Bernat, M. Petit, M. Afanassieff, S. Markossian, A. Malashicheva, R. lacone, K. Anastassiadis, P. Savatier, A short $G_{1}$ phase is an intrinsic determinant of naïve embryonic stem cell pluripotency. Stem Cell Res. 10, 118-131 (2013).

7. Y. Sela, N. Molotski, S. Golan, J. Itskovitz-Eldor, Y. Soen, Human embryonic stem cells exhibit increased propensity to differentiate during the $G_{1}$ phase prior to phosphorylation of retinoblastoma protein. Stem Cells 30, 1097-1108 (2012).

8. A. M. Singh, J. Chappell, R. Trost, L. Lin, T. Wang, J. Tang, B. K. Matlock, K. P. Weller, H. Wu, S. Zhao, P. Jin, S. Dalton, Cell-cycle control of developmentally regulated transcription factors accounts for heterogeneity in human pluripotent cells. Stem Cell Reports $\mathbf{1}$, 532-544 (2013).

9. S. Dalton, Linking the cell cycle to cell fate decisions. Trends Cell Biol. 25, 592-600 (2015).

10. C. D. Allis, T. Jenuwein, The molecular hallmarks of epigenetic control. Nat. Rev. Genet. 17, 487-500 (2016).

11. B. Schuettengruber, H. M. Bourbon, L. Di Croce, G. Cavalli, Genome regulation by polycomb and trithorax: 70 years and counting. Cell 171, 34-57 (2017).

12. T. I. Lee, R. G. Jenner, L. A. Boyer, M. G. Guenther, S. S. Levine, R. M. Kumar, B. Chevalier, S. E. Johnstone, M. F. Cole, K.-I. Isono, H. Koseki, T. Fuchikami, K. Abe, H. L. Murray, J. P. Zucker, B. Yuan, G. W. Bell, E. Herbolsheimer, N. M. Hannett, K. Sun, D. T. Odom, A. P. Otte, T. L. Volkert, D. P. Bartel, D. A. Melton, D. K. Gifford, R. Jaenisch, R. A. Young, Control of developmental regulators by polycomb in human embryonic stem cells. Cell 125, 301-313 (2006).

13. L. A. Boyer, K. Plath, J. Zeitlinger, T. Brambrink, L. A. Medeiros, T. I. Lee, S. S. Levine, M. Wernig, A. Tajonar, M. K. Ray, G. W. Bell, A. P. Otte, M. Vidal, D. K. Gifford, R. A. Young, R. Jaenisch, Polycomb complexes repress developmental regulators in murine embryonic stem cells. Nature 441, 349-353 (2006).

14. J. K. Stock, S. Giadrossi, M. Casanova, E. Brookes, M. Vidal, H. Koseki, N. Brockdorff, A. G. Fisher, A. Pombo, Ring1-mediated ubiquitination of $\mathrm{H} 2 \mathrm{~A}$ restrains poised RNA polymerase II at bivalent genes in mouse ES cells. Nat. Cell Biol. 9, 1428-1435 (2007).

15. M. G. Guenther, S. S. Levine, L. A. Boyer, R. Jaenisch, R. A. Young, A chromatin landmark and transcription initiation at most promoters in human cells. Cell 130, 77-88 (2007).

16. B. E. Bernstein, T. S. Mikkelsen, X. Xie, M. Kamal, D. J. Huebert, J. Cuff, B. Fry, A. Meissner, M. Wernig, K. Plath, R. Jaenisch, A. Wagschal, R. Feil, S. L. Schreiber, E. S. Lander, A bivalent chromatin structure marks key developmental genes in embryonic stem cells. Cell 125, 315-326 (2006).

17. V. Azuara, P. Perry, S. Sauer, M. Spivakov, H. F. Jørgensen, R. M. John, M. Gouti, M. Casanova, G. Warnes, M. Merkenschlager, A. G. Fisher, Chromatin signatures of pluripotent cell lines. Nat. Cell Biol. 8, 532-538 (2006).

18. D. Landeira, S. Sauer, R. Poot, M. Dvorkina, L. Mazzarella, H. F. Jørgensen, C. F. Pereira, M. Leleu, F. M. Piccolo, M. Spivakov, E. Brookes, A. Pombo, C. Fisher, W. C. Skarnes, T. Snoek, K. Bezstarosti, J. Demmers, R. J. Klose, M. Casanova, L. Tavares, N. Brockdorff, M. Merkenschlager, A. G. Fisher, Jarid 2 is a PRC2 component in embryonic stem cells required for multi-lineage differentiation and recruitment of PRC1 and RNA polymerase II to developmental regulators. Nat. Cell Biol. 12, 618-624 (2010).

19. D. Pasini, P. A. C. Cloos, J. Walfridsson, L. Olsson, J.-P. Bukowski, J. V. Johansen, M. Bak, N. Tommerup, J. Rappsilber, K. Helin, JARID2 regulates binding of the polycomb repressive complex 2 to target genes in ES cells. Nature 464, 306-310 (2010). 
20. X. Shen, W. Kim, Y. Fujiwara, M. D. Simon, Y. Liu, M. R. Mysliwiec, G.-C. Yuan, Y. Lee, S. H. Orkin, Jumonji modulates polycomb activity and self-renewal versus differentiation of stem cells. Cell 139, 1303-1314 (2009).

21. J. C. Peng, A. Valouev, T. Swigut, J. Zhang, Y. Zhao, A. Sidow, J. Wysocka, Jarid2/Jumonji coordinates control of PRC2 enzymatic activity and target gene occupancy in pluripotent cells. Cell 139, 1290-1302 (2009).

22. G. Li, R. Margueron, M. Ku, P. Chambon, B. E. Bernstein, D. Reinberg, Jarid2 and PRC2, partners in regulating gene expression. Genes Dev. 24, 368-380 (2010).

23. M. Beringer, P. Pisano, V. di Carlo, E. Blanco, P. Chammas, P. Vizán, A. Gutiérrez, S. Aranda, B. Payer, M. Wierer, L. di Croce, EPOP functionally links elongin and polycomb in pluripotent stem cells. Mol. Cell 64, 645-658 (2016).

24. S. Hauri, F. Comoglio, M. Seimiya, M. Gerstung, T. Glatter, K. Hansen, R. Aebersold, R. Paro, M. Gstaiger, C. Beisel, A high-density map for navigating the human polycomb complexome. Cell Rep. 17, 583-595 (2016).

25. A. Sakaue-Sawano, H. Kurokawa, T. Morimura, A. Hanyu, H. Hama, H. Osawa, S. Kashiwagi, K. Fukami, T. Miyata, H. Miyoshi, T. Imamura, M. Ogawa, H. Masai, A. Miyawaki, Visualizing spatiotemporal dynamics of multicellular cell-cycle progression. Cell 132, 487-498 (2008).

26. L. Windhager, T. Bonfert, K. Burger, Z. Ruzsics, S. Krebs, S. Kaufmann, G. Malterer, A. L'Hernault, M. Schilhabel, S. Schreiber, P. Rosenstiel, R. Zimmer, D. Eick, C. C. Friedel, L. Dölken, Ultrashort and progressive 4sU-tagging reveals key characteristics of RNA processing at nucleotide resolution. Genome Res. 22, 2031-2042 (2012).

27. A. J. Rutkowski, L. Dölken, High-resolution gene expression profiling of RNA synthesis, processing, and decay by metabolic labeling of newly transcribed RNA using 4-thiouridine. Methods Mol. Biol. (Clifton, N.J.) 1507, 129-140 (2017).

28. E. Brookes, A. Pombo, Modifications of RNA polymerase II are pivotal in regulating gene expression states. EMBO Rep. 10, 1213-1219 (2009)

29. G. Caretti, D. Palacios, V. Sartorelli, P. L. Puri, Phosphoryl-EZH-ion. Cell Stem Cell 8 , 262-265 (2011).

30. R. Liefke, V. Karwacki-Neisius, Y. Shi, EPOP interacts with elongin BC and USP7 to modulate the chromatin landscape. Mol. Cell 64, 659-672 (2016).

31. A. M. Singh, Y. Sun, L. Li, W. Zhang, T. Wu, S. Zhao, Z. Qin, S. Dalton, Cell-cycle control of bivalent epigenetic domains regulates the exit from pluripotency. Stem Cell Reports $\mathbf{5}$, 323-336 (2015).

32. L. Morey, A. Santanach, L. Di Croce, Pluripotency and epigenetic factors in mouse embryonic stem cell fate regulation. Mol. Cell. Biol. 35, 2716-2728 (2015).

33. R. Margueron, D. Reinberg, The polycomb complex PRC2 and its mark in life. Nature 469, 343-349 (2011).

34. H. L. Sladitschek, P. A. Neveu, MXS-chaining: A highly efficient cloning platform for imaging and flow cytometry approaches in mammalian systems. PLOS ONE 10, e0124958 (2015)

35. D. Landeira, H. Bagci, A. R. Malinowski, K. E. Brown, J. Soza-Ried, A. Feytout, Z. Webster, E. Ndjetehe, I. Cantone, H. G. Asenjo, N. Brockdorff, T. Carroll, M. Merkenschlager, A. G. Fisher, Jarid 2 coordinates nanog expression and PCP/Wnt signaling required for efficient ESC differentiation and early embryo development. Cell Rep. 12, 573-586 (2015).

36. E. Brookes, I. de Santiago, D. Hebenstreit, K. J. Morris, T. Carroll, S. Q. Xie, J. K. Stock, M. Heidemann, D. Eick, N. Nozaki, H. Kimura, J. Ragoussis, S. A. Teichmann, A. Pombo, Polycomb associates genome-wide with a specific RNA polymerase II variant, and regulates metabolic genes in ESCs. Cell Stem Cell 10, 157-170 (2012).

37. T. S. Mikkelsen, M. Ku, D. B. Jaffe, B. Issac, E. Lieberman, G. Giannoukos, P. Alvarez, W. Brockman, T.-K. Kim, R. P. Koche, W. Lee, E. Mendenhall, A. O'Donovan, A. Presser, C. Russ, X. Xie, A. Meissner, M. Wernig, R. Jaenisch, C. Nusbaum, E. S. Lander, B. E. Bernstein, Genome-wide maps of chromatin state in pluripotent and lineagecommitted cells. Nature 448, 553-560 (2007).
38. M. Ku, R. P. Koche, E. Rheinbay, E. M. Mendenhall, M. Endoh, T. S. Mikkelsen, A. Presser, C. Nusbaum, X. Xie, A. S. Chi, M. Adli, S. Kasif, L. M. Ptaszek, C. A. Cowan, E. S. Lander, H. Koseki, B. E. Bernstein, Genomewide analysis of PRC1 and PRC2 occupancy identifies two classes of bivalent domains. PLOS Genet. 4, e1000242 (2008).

39. H. Kobayashi, T. Sakurai, M. Imai, N. Takahashi, A. Fukuda, O. Yayoi, S. Sato, K. Nakabayashi, K. Hata, Y. Sotomaru, Y. Suzuki, T. Kono, Contribution of intragenic DNA methylation in mouse gametic DNA methylomes to establish oocyte-specific heritable marks. PLOS Genet. 8, e1002440 (2012).

40. A. Dobin, T. R. Gingeras, Mapping RNA-seq reads with STAR. Curr. Protoc. Bioinformatics 51, 11.14.11-11.14.19 (2015).

41. H. Li, B. Handsaker, A. Wysoker, T. Fennell, J. Ruan, N. Homer, G. Marth, G. Abecasis, R. Durbin; 1000 Genome Project Data Processing Subgroup, The sequence alignment/ map format and SAMtools. Bioinformatics 25, 2078-2079 (2009).

42. F. Ramírez, D. P. Ryan, B. Grüning, V. Bhardwaj, F. Kilpert, A. S. Richter, S. Heyne, F. Dündar, T. Manke, deepTools2: A next generation web server for deep-sequencing data analysis. Nucleic Acids Res. 44, W160-W165 (2016).

43. E. Kopylova, H. Touzet, L. Noé, SortMeRNA: Fast and accurate filtering of ribosomal RNAs in metatranscriptomic data. Bioinformatics 28, 3211-3217 (2012).

44. M. D. Robinson, A. Oshlack, A scaling normalization method for differential expression analysis of RNA-seq data. Genome Biol. 11, R25 (2010).

45. S. Tarazona, P. Furió-Tarí, D. Turrà, A. Di Pietro, M. J. Nueda, A. Ferrer, A. Conesa, Data quality aware analysis of differential expression in RNA-seq with NOISeq R/Bioc package. Nucleic Acids Res. 43, e140-e140 (2015).

46. H. Marks, T. Kalkan, R. Menafra, S. Denissov, K. Jones, H. Hofemeister, J. Nichols, A. Kranz A. Francis Stewart, A. Smith, H. G. Stunnenberg, The transcriptional and epigenomic foundations of ground state pluripotency. Cell 149, 590-604 (2012).

Acknowledgments: We are very grateful to A. Pombo, E. Brookes, and L. Dölken for sharing in house protocols and technical advice for Ser-RNAPII and 4sU-seq analyses; to L. Di Croce for sharing EPOP and EloB homemade antibodies and providing scientific advice; and to core facilities in GENYO and in particular, to the flow cytometry and genomics units. We also thank the genomics unit at the CRG for assistance with ChIP-seq experiments. This study was supported by the Spanish Ministry of Economy and Competitiveness (SAF2013-40891-R and BFU2016-75233-P) and the Andalusian Regional Government (PC-0246-2017). D.L. is a Ramón y Cajal researcher of the Spanish Ministry of Economy and Competitiveness (RYC-2012-10019). Author contributions: D.L. designed the study. H.G.A. and D.L. wrote the manuscript. H.G.A., A.G., L.L.-O., and I.T. designed, performed, and analyzed experiments. J.M.-M. and P.C.-S. carried out bioinformatic analysis. Competing interests: The authors declare that they have no competing interests. Data and materials availability: All data needed to evaluate the conclusions in the paper are present in the paper and/or the Supplementary Materials. Datasets are available at GEO-NCBI with accession number GSE128851 (www.ncbi.nlm.nih. gov/geo/query/acc.cgi?acc=GSE128851). Additional data related to this paper may be requested from the authors.

Submitted 22 June 2019

Accepted 11 December 2019

Published 4 March 2020

$10.1126 /$ sciadv.aay4768

Citation: H. G. Asenjo, A. Gallardo, L. López-Onieva, I. Tejada, J. Martorell-Marugán, P. Carmona-Sáez, D. Landeira, Polycomb regulation is coupled to cell cycle transition in pluripotent stem cells. Sci. Adv. 6, eaay4768 (2020). 


\section{ScienceAdvances}

\section{Polycomb regulation is coupled to cell cycle transition in pluripotent stem cells}

Helena G. Asenjo, Amador Gallardo, Lourdes López-Onieva, Irene Tejada, Jordi Martorell-Marugán, Pedro Carmona-Sáez and David Landeira

Sci Adv 6 (10), eaay 4768.

DOI: $10.1126 /$ sciadv.aay4768

ARTICLE TOOLS

SUPPLEMENTARY MATERIALS

REFERENCES

PERMISSIONS http://advances.sciencemag.org/content/6/10/eaay4768

http://advances.sciencemag.org/content/suppl/2020/03/02/6.10.eaay4768.DC1

This article cites 46 articles, 4 of which you can access for free http://advances.sciencemag.org/content/6/10/eaay4768\#BIBL

http://www.sciencemag.org/help/reprints-and-permissions

Science Advances (ISSN 2375-2548) is published by the American Association for the Advancement of Science, 1200 New York Avenue NW, Washington, DC 20005. The title Science Advances is a registered trademark of AAAS.

Copyright @ 2020 The Authors, some rights reserved; exclusive licensee American Association for the Advancement of Science. No claim to original U.S. Government Works. Distributed under a Creative Commons Attribution NonCommercial License 4.0 (CC BY-NC). 